233

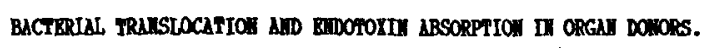

R.P.Bleichrodt, Bs.van Goor, A.L.Scholte, C.Roswan, R.Rooi, J.Grond.

The mucosa of the GI-tract provides an effective barrier to the entry of intestinal bacteria and endotoxins. As show in anival experiments this barrier function can be lost in critical illness and thus way lead to translocation of bacteria and endotoxins, resulting in bacteraevia, endogenous infections and endotoxaevia. Since hardly any infornation is present about these phenowena in huwans without (preexistent) GI-tract disease, we did a prospective study in organ donors because they are at risk for bacterial translocation and endotoxin absorption.

Materials and wetbods: Twenty-one organ donors (nean age 26, range 3-58 years) entered the study. Before surgery a bloodsanple was taken fron the peripheral blood for culture, endotorin level and endotoxin inactivating activity (BIL). sfter laparotony a sanple of abdoninal fluid was taken for culture and endotoxin level. Subsequently nesenteric lynfnodes (KLW) vere sampled at the proxinal jejunum, the distal jejunum and the distal ileun for culture. Before starting organ perfusion a bloodsanple was taken fron the portal vein for culture, endotoxin level and BIA. After renoval of the organs biopsies were taken of the lung, spleen and liver, for culture and from the prosinal jejunun, the distal jejunun, the distal ilew and the caecur for light and electron nicroscopy and culture. cultures were considered positive as nore than $10^{2} \mathrm{cfu} / \mathrm{gran}$ tissue or $>10^{2} \mathrm{cfu} / \mathbf{m}$ fluid were isolated.

Results: Positive cultures were found in the kall of 11 donors, in the lung of 7 , in the liver of 2 , in the spleen of 5 and in the peripheral blood of 1 donor. All cuitures of portal blood and peritoneal fluid were negative. Three tines only gran negative bacteria were isolated, 19 tines only gran positives and 4 times both. AIl but five of the isolated strains were also isolated fron the suall bowel. Elevated plasna endotoxin levels $(>5 \mathrm{pg} / \mathrm{nl})$ in the peripheral blood were found in 4 donors, in the portal blood in 2 donors and in peritoneal fluid in $9 / 17$ donors. The eIA (nean $5 \mathrm{SD}, \mu \mathrm{g} / \mathbf{n l}$ ) in both peripheral $(2.25 \pm 2.9)$ and portal blood $(1.94 \pm 2.6)$ were significantiy ( $p<$ 0.0001 ) lover as in a reference group of healthy individuals (8ะ1). Ho ucosal danage was found in the biopsies.

conclusion: Bacterial translocation is a comon feature in organ donors and is probably freguently accoupanied with endotoxin absorption leading to endotoxaeria and/or decreased endotoxin inactivating capacity.

Twenteborg Hospital. $7600 \mathrm{SZ}$ Almelo. Netherlands

\section{Nosocomial pneumonia prophylaxis}

\section{5}

UTILTTY OF SELECTIVE DIGESTIVE DECONTAMINATION IN A GENERAL POPULATION OF MECHANICALLY VENTILATED PATIENTS M. Ferrer, A. Torres, J. González, J. Puig de la Bellacasa, J.M. Gatell, M. Roca, M.T. Jiménez de Anta, R. Rodriguez-Roisin.

To assess the utility of selective digestive decontamination (SDD) in the prophylaxis of nosocomial respiratory tract infections in a general population of mechanically ventilated (MV) patients, we performed a prospective randomized double-blind clinical study using an association of Polymyxin E, Tobramycin and Amphotericin B topically in the oropharynx and through a nasogastric tube versus placebo. Eighty MV patients have been studied (56 males and 24 females), aged $61 \pm 19$ yrs (mean $\pm S D$ ). Thirty-nine patients received antibiotic association and 41 received placebo. Patients received Cefotaxime (2 $\mathrm{g} / 6 \mathrm{~h}$ ) during 4 days to prevent the primary endogenous infection, except when another antibiotic treatment was necessary. The overall incidence of nosocomial pneumonia and purulent bronchitis was $24 \%$ and the mortality rate was $29 \%$. There were not significant differences between both groups (SDD and placebo) regarding the incidence of pneumonia and purulent bronchitis (23\% v $24 \%$ respectively), the mortality rate ( $31 \%$ vs $27 \%$ ), the duration of MV (13.5 vs 12.6 days) and the length of ICU hospitalization (15.3 vs 14.3 days). By contrast, the SDD group showed a significant lower sate of bronchial colonization by gram negative bacilli ( $31 \%$ vs $78 \%, p<0.00003$ ) and particularly by $P$. acruginosa (23\% vs 67\%, $p<0.0004)$, and by Candida (21\% vs $40 \%, \mathrm{p}<0.059)$. These differences were similar in pharyngeal and in gastric'colonization. Although it was not statistically significant, colonization by methicillin-resistant $S$. aureus (MRSA) was higher in the SDD gToup ( $36 \%$ vs $30 \%$ in bronchial aspirates and $33 \%$ vs $18 \%$ in pharyngeal swabs). The most frequent microorganisms causing nosocomial pneumonia in both groups were P. aeruginosa and MRSA. Three cases of $P$. aeruginosa pneumonia in the SDD group were exogenous and three cases in the placebo group were endogenous. MRSA pneumonias in both groups were endogenous. Our results suggest that, although SDD is useful in the prevention of pharyngeal and bronchial colonization by gram negative bacilli, this treatment does not reduce the overall incidence of nosocomial respiratory Iract infections and the mortality rate in a general population of MV patients. The different pathogenesis of gram negative preumonia in both SDD and placebo group should be confirmed in further studies.

Serveis de Pneumología, Microbiologia, Malaltíes Infeccioses i Farmacia. Hospital Clínic. Universitat de Barcelona. Villarroel 170.08036 Barcelona. Spain.

\section{4}

TIE CLINICAL VALIDITY OF TESTING ENDOTOXIN IN SEVERE SEPSIS/SIIOCK IN ICU PATIENTS

B.M. Hameter P. Westra F.L. van der Zande A.A.T.M.M. Vinks R. Lieuwen D.J. Touw J.A.M. de Haas

Early treatment, within $24 \mathrm{~h}$ maximally, can be desirable in persisting septic shock, associated with a high mortality. Quick and highly predicting procedures for identification of the type of infection still remain a big problem. Besides fully supportive and appropriate antibiotic therapy, today adjunctive immunotherapy with antibodies against endotoxin (HA-1A, Centoxin ${ }^{\star}$ ) is available (Ziegler EJ et al., N Engl J Med 1991; 324; 429).

Objective: to evaluate the effectiveness of determination of endotoxin (LPS) to identify endotoxemia, as a predictor of gram-negative infection; a retrospective survey after ICU admission.

The LPS concentration in serum samples was determined using the Coatest Endotoxin test by KabiVitrum, Sweden. The assay was modified for measuring in serum or plasma. Serum samples were diluted 10 -fold with endotoxinfree water and heated at $75-80^{\circ}$ Celsius for 5 minutes. After cooling to room temperature, $25 \mu \mathrm{L}$ of the pretreated solution is brought to $37^{\circ}$ Celsius. After 4 minutes, $25 \mu \mathrm{L}$ LAL-solution is added to each tube and the solution is stirred. Incubation time is 30 minutes. Next, $50 \mu \mathrm{L}$ of the $\mathbf{S 2 3 2 4}$ chromogen substrate / buffer ( 1 : I) solution is added and stirred again. After another 5 minutes the reaction is terminated by adding $50 \mu \mathrm{L} 50 \%$ acetic acid. After adding $450 \mu \mathrm{L}$ water, the extinction was measured at $405 \mathrm{~nm}$ immediately.

Concentrations were determined by reading them from a standard curve. The sensitivity of the assay was about $25 \mathrm{pg} \mathrm{mL}^{-1}$, while the time needed for the assay was $3 \mathrm{~h}$, maximally, with a capacity of is samples in duplo.

14 ICU patients with septic shock were included; the mortality was $43 \%$, half of which was due to sepsis. Results: $71 \%$ showed endotoxemia $(57 \pm 30$ $\mathrm{pg} \mathrm{nL}^{-1}$, range $\left.26-121 \mathrm{pg} \mathrm{mL}^{-1}\right)$. Three patients received adjunctive immunotherapy with HA-1A, $100 \mathrm{mg}$, and they survived. One patient received a second dose, 3 days after the first.

In conclusion:

- LPS measurement in septic shock can be of diagnostic and therapeutic value and provides a quick tool $(<3 \mathrm{~h})$ in comparison with conventional blood culture techniques, which take $24-48 \mathrm{~h}$. These are, however, of obligate value for indentification of the infection.

Central Pharmacy of The Hague Hospitals, P.O. Box 43100, NL-2504 AC The Hague, The Netherlands

\section{6} PROPHYLAXIS OF PNEUMONIA IN MECHANICALLY
VENTILATED PATIENTS BY CONTINUOUS SUBGLOTTIC ASPIRATION.

J. Vallés, N. Bonsoms, LI. Blanch, F. Baigorri, D. Fontanals*, P. Saura, A. Artigas

In the pathogenesis of endogenous ventilator-associated nosocomial pneumonia (NP), the relationship between chronic aspiration through a tracheal cutt and the development of pneumonia is well established.

The aim of this study was to evaluate the efficiency of continuous suction of subglottic secretions (SS) accumulated above the cutf in the prevention of nosocomial pneumonia in mechanically ventilated patients.

Method. This prospective study was conducted on 123 patients under mechanical ventilation (MV) for more than 72 hours. They were randomized and divided into two groups: Group $\mid(n=60)$ underwent continuous aspiration of SS and Group II $(n=63)$ didn't receive aspiration. Both groups were intubated with a special tracheal tube (TT)(Hi-lo-evac. Mallinckrodt) were intubated with a special tracheal tube (TT)(Hi-lo-evac. Mallinckrodt)
which disposes of an additional lumen in order to suction the accumulated secretions above the cuff. During the period of study, pressure of the TT cuff was checked every 4 hours in both groups. In Group I, total amount aspirated SS was measured every day and semiquantitative culture was performed each 5 days. Protected specimen brush (PSB) and bronchoalveolar lavage (BAL) were pertormed in patients who fulfilled the established standard criteria for NP.

Results. Both groups were similar in terms of demographic characteristics. severity of iliness (APACHE it), mortality risk and risk factors for NP. Treatment with antimicrobial agents was significantly higher in Group I ( $91.7 \%)$ vs Group II (68.3\%) (p<0.05). NP developed in $26(21.1 \%)$ of the 123 patients studied, $9(15 \%)$ in Group I and $17(27 \%)$ in Group II $(p=0.159)$ $P$. aenuginosa was the most frequent bacteria isolated in PSB and BAL. The mean ( \pm SD) number of days until development of NP was 11.4 \pm 6.7 in Group $I$ and $6.47 \pm 3.45$ in Group II $(p<0.05)$.

Discuselon. These results indicate a tendency to reduce the risk of NP in patients with MV for more than 3 days when SS are continuously aspitrated. However, further studies will be needed to confirm the validity of this method of prophylaxis.

Depts. of Intensive Care and Microbiology", Hospital de Sabadell, 08028 Sabadell- SPAIIN.

(Supported in part by FISS 9210184) 
SELECTIVE DECONTAMINATION OF THE DIGESTIVE TRACT AND EARLY SYSTEMIC CEFOTAXIME IN PATIENTS WITH BLUNT TRAUMA: EFFECT ON INFECTION AND MORTALITY

\section{G.J. Dobb, S.M. Boyle}

Selective decontamination of the digestive tract (SDD) with antimicrobial drugs has been shown to reduce the frequency of upper airway colonisation and respiratory tract infection. The aim of this study was to determine the effect of SDD on respiratory infection and mortality in patients admitted to an intensive care unit with blunt trauma who needed tracheal intubation for at least 2 days.

The patients were a predefined sub-group from a larger study of SDD in which patients treated with SDD between December 1988 and December 1989 are compared with controls from the preceding and following years. Patients were matched by diagnostic category, APACHE II score, age and sex. The SDD regimen was a polymyxin, gentamicin and amphotericin B paste applied to the buccal mucosa 6 hourly, the same antibiotics in suspension given nasogastrically 6 hourly and cefotaxime $1 \mathrm{gm} 6$ hourly for the first 4 days.

The mean $( \pm S D)$ age, APACHE II score and injury severity scores in the pre-SDD $(n=67)$, SDD $(n=68)$ and post-SDD $(n=51)$ groups were $33.6 \pm 18.1$ $33.7 \pm 17.1$ and $35.8 \pm 19.2$ years; $11.6 \pm 5.6,12.5 \pm 6.6$ and $12.3 \pm 6.4$ points; and $24.2 \pm 12.1,28.4 \pm 14.4$ and $23.9 \pm 12.3$ points respectively. The frequency of nosocomial pneumonia was $55 \%, 35 \%$ and $59 \%$ in the successive groups (Chi-square $8.12, p=0.017$ ). The frequency of positive cultures from wounds, urine, blood, intravascular catheters or sputum during the first 4 days was similar in the 3 groups. After 4 days the frequency of bacterial isolates from wounds, urine, blood and intravascular catheters remained similar but there was a significant difference in positive sputum cultures: $28 \%, 12 \%$ and $18 \%$ in successive groups (Chi-square $6.1, \mathrm{p}=0.048$ ). Variations in Gram-negative bacterial isolates caused this difference.

Mortality was $16 \%, 3 \%$ and $10 \%$ in successive groups (Chi-square $7.0, p=0.03$ odds ratio SDD vs controls $0.19,95 \%$ confidence interval $(0.04-0.92)$.

Patients with blunt trauma treated with SDD had a lower frequency of nosocomial pneumonia, positive sputum cultures after 4 days and death.

Intensive Care Unit, Royal Perth Hospital, Wellington Street, Perth 6000, Western Australia.

\section{9}

\section{OROPHARYNGEAL GENTAMICIN FOR LONG-TERM VENTILATED PATIENTS ON SUCRALFATE?}

\section{A.N. Laggner, M. Tryba\#, A. Georgopoulos*, K. Lenz§, G. Grimm§, W.Graninger*, B.Schneeweiß§, W.Druml+}

Sucralfate has been demonstrated to reduce incidence of stress ulcer bleeding and nosocomial pneumonia in long-term ventilated patients. In a placebo-controlled trial we studied, whether gentamicin administered topically to the oropharynx (OPG) had additional clinical benefits in patients on mechanical ventilation for $\geq 5$ days and stress ulcer prophylaxis with sucralfate $(6 \times 1 \mathrm{~g} /$ day $)$

In the OPG group $(n=33) 40 \mathrm{mg}$ gentamicin and in the control group $(n=34) 5 \%$ dextrose were administered to the oropharynx 4 times per day. During OPG pharyngeal colonization rate (21 vs $44 \%)$ and tracheal secretion colonization rate $(12$ vs $41 \%)$ were significantly lower than during placebo $(p<0.05)$. Despite these differences nosocomial pneumonia rate ( 3 vs $12 \%$ ) duration of intubation $(9.5+4.8$ vs $7.9+3.5$ days) and mortality $(27$ vs $41 \%$ ) were not significantly affected by OPG. Moreover, 13 of 15 bacteria (87\%) that occurred during $O P G$ were resistant to gentamicin

Despite its reduction of bacterial colonization rates of pharyngeal and tracheal secretions OPG did not seem to offer additional clinical benefits in long-term mechanically ventilated patients on stress ulcer prophylaxis with sucralfate

From the Emergency Department, $1 .^{*}, 3 .+$, and 4.§ Dept. of Internal Medicine, University of Vienna, Austria; and University Clinic of Anesthesiology, Intensive Care and Pain Therapy, Bochum, Germany\#
THE EFFECT OF TOPICAL ANTIMICROBIAL PROPHYLAXIS ON COLONI ZATION OF OROPHARYNX, STOMACH AND TRACHEA IN PATIENTS RECEIVING AND NOT-RECEIVING PROPHYLAXIS

M. BONTEN*, C. GAILLARD, F. VAN TIEL, S, VAN DER GEEST, E. STOBBERINGH. University Hospital Maastricht, The Netherlands.

Topical antinicrobial prophylaxis (TAP) with non-absorbable antibiotics has been used to prevent nosocomial pneumonia in mechanically ventilated patients (pts). Since colonization is modulated by TAP, both colonization of pts not receiving TAP as wel as cross-acquisition could be influenced. Colonization was studied in 2 identica general ICUs'. Pts in group 1 (ICU $I, n=24$ ) received TAP while pts in group 2 (ICU I, $n=41$ ) and group 3 (ICU II, $n=32$ ) received no TAP. TAP consisted of: (a) $1 \mathrm{ml}$ Tobramycin (T) $(8 \mathrm{mg} / \mathrm{ml}) /$ Colistin (C) $(5 \mathrm{mg} / \mathrm{ml})$ in each nostril and $5 \mathrm{ml}$ by nasogastric tube, (b) application in oropharynx of T/C/Amphotericin B (A) $2 \%$ in Orabase, (c) suspension of $0.5 \mathrm{ml} \mathrm{A}(100 \mathrm{mg} / \mathrm{ml})$ in each nostril and $2.5 \mathrm{ml}$ by nasogastric tube, (d) $1 \mathrm{~g}$ sucralfate, all 4 times daily. TAP included no systemic antibiotics. Oropharyngeal swabs $(O)$, tracheal $(T r)$ and gastric aspirates $(\mathrm{C})$ were cultured on admission and subsequently at least twice a week. The 3 groups were comparable for age, APACHE II-score and colonization on admission.

Table 1 shows the number of pts, $>5$ days in ICU, with persistent negative cultures (110) and acquired colonization in $\mathrm{O}, \mathrm{G}$ and $\mathrm{Tr}$ with Enterobactericaeac (Eb) and Pseudomonas aeruginosa (Ps); ${ }^{*}=\mathrm{p}<.05$ as compared to group 3:

\begin{tabular}{|c|c|c|c|c|c|c|c|c|c|c|}
\hline \multirow[b]{2}{*}{$\mathrm{gr}:$} & \multirow[b]{2}{*}{$\mathrm{n}:$} & \multicolumn{3}{|c|}{ Oroph.: } & \multicolumn{3}{|c|}{ Gastric asp:: } & \multicolumn{3}{|c|}{ Tracheal asp.: } \\
\hline & & no & $E_{b}$ & Ps & no & $\mathrm{El}$ & Ps & no & $\mathrm{Eb}$ & Ps \\
\hline 1 & 22 & $4^{*}$ & $3 *$ & $1^{*}$ & 4 & $3 *$ & 1 & $6 *$ & 4 & 2 \\
\hline 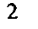 & 18 & $4^{*}$ & $2^{*}$ & $1^{*}$ & 3 & 5 & 0 & 3 & 4 & 2 \\
\hline $\mathbf{3}$ & 23 & 0 & 10 & 7 & 1 & 9 & 2 & 1 & 9 & \\
\hline
\end{tabular}

Table 2 shows the percentages of pts colonized with Enterococcus faecalis $(\mathrm{Et})$ in $\mathrm{O}$ $G$ and $T r$ according to the duration of stay on the $\mathrm{ICU} ;^{*}=p<.05$ as compared to group 3:

days: $\quad 2.6 \quad 7-13 \geq 14$

$\begin{array}{llll}\text { days: } & 2.6 & 7-13 & \geq 14 \\ \text { gr. } & 18 & 29 & 46\end{array}$

$\begin{array}{llll}\text { gr. } 2 & 6 & 13 & 43\end{array}$

$\begin{array}{llllllll}\text { gr.3 } 3 & 9 & 15 & 3 * & 5 & 15 & 0 & 0\end{array}$

Conclusion: TAP decreased colonization in oropharynx, stomach and trachea with El and $\mathrm{Ps}$, but tended to increase colonization with $\mathrm{Ef}$ in oropharynx and stomach in treated and untreated pts in the same $\mathrm{KCU}$, as compared to pts in another $\mathrm{JCU}$.
240

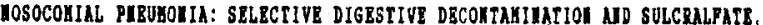

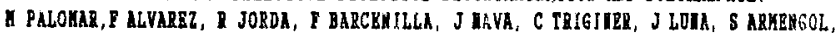
B QUINAMA UDD J GBLABERT.

Io conpare the offects of Selective Blgestive Decontanination (SDD) and sulcralfate on patient's coloditation, aosoconjal paeunania (IPB) ad othor lafectioss, wo conducted a prospective, randenised, nulticentro (10 hospitals) study. Inclusion criteria were: Pationts not Infected (any location) at the the of laciugion, not receiving antibiotic therapy, end requiring nechanical vostilation 44 days. Those with aBDS, leakoponia or pregnant vere exciuded. Patients roro assigned into 3 groups (Gr): 6r I or Control (C) rocieved only antiacids or h2-blockers; Gr II (sDD) oral and gastric decontanination nith polynirio \& tobrangcia ad aphotericin B. every 6 hours for the period of endotracteel istubation, and cefotaxine (CTA) 1 gr IV evory o hours, (days; Gr III (S) recelved I gr overy 6 hours by aasogastric tube for the period of Iatubation and CrI 4 days. Bacterlological survillance cultures (orophariageal and rectal swabs, tracheal and gastric aspirated, urine) wero done twice weekly. Iafection were diegaosed accordiag to CDC criteris, end reconendated high senaltivity nethods for MPa. Statistical anelysis was perforned by chl-square. Irushal-hallis ad laina-Thitney tests.

lesslts: 150 pationts wore studied, a1 woro exciuded bocanse early extubation or deatb. All patieats vere conparablo for age, sex and APACHB II scoses. The Incidence of IPa was $501(21 / 42)$ ID $C, 178(7 / 41)$ in SDD and 30.43 (18/46) in $8, p=0.005$, vitb no significant difforeace betren $C$ and 8 groups. Burly IPa $(1-5$ deys) appeared aore frecuently in $C$ group, 61.9 \&, thas in SDD $28.57 \%$ or 8 groups $16.68, p=0.01$. Infection rate nas 39.58 in $\mathrm{C}$ group, 398 in SDD and 54.38 in $S, p=0.15$, but ourly

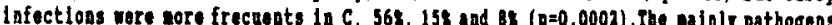
cavilag lafections vere Gras aegative lo $C$ and 5 groups respect 8DD, 38.48 , 69.2 and $31.68(p=0.025)$. Io difference in total cortality rates was observed betwea the 3 groups (28.58, 23.58 asd 21.78) except whon trauna patienta were analised separtely, 36.98, o and 168 ( $p=0.006)$.

Cosclusions: SDD reduced the Incidance of IPa in veatllated patients, but $S$ did not. the overell infection rate was not significently reducod ho SDD and $S$ groups, but infectloas appeared later than in control group. Gran negatives bacterlas were less frecuent in SDD group lafections. Nortality rate decreased onily in SDD trauna pationts.

Iatensive Care Vait. Joiversity Ganeral Hospital Vall d'Hebrón

Pe Vall d'Bebron $8 / \mathrm{n} .09035$ Barcelone.Spaids. 